Supporting Information

\title{
From carbon-encapsulated iron nanorods to short carbon
}

\section{nanotubes}

Junping Huo, Huaihe Song*, Xiaohong Chen, Bin Cheng

State Key Laboratory of Chemical Resource Engineering, Beijing University of Chemical

Technology, 100029, Beijing, P.R. China

*Corresponding author, E-mail: songhh@ mail.buct.edu.cn (H. Song)

Tel: +86-10-64434916 Fax: +86-10-64437587

\section{SI-1 TEM image and XRD patterns of carbon nanotubes}

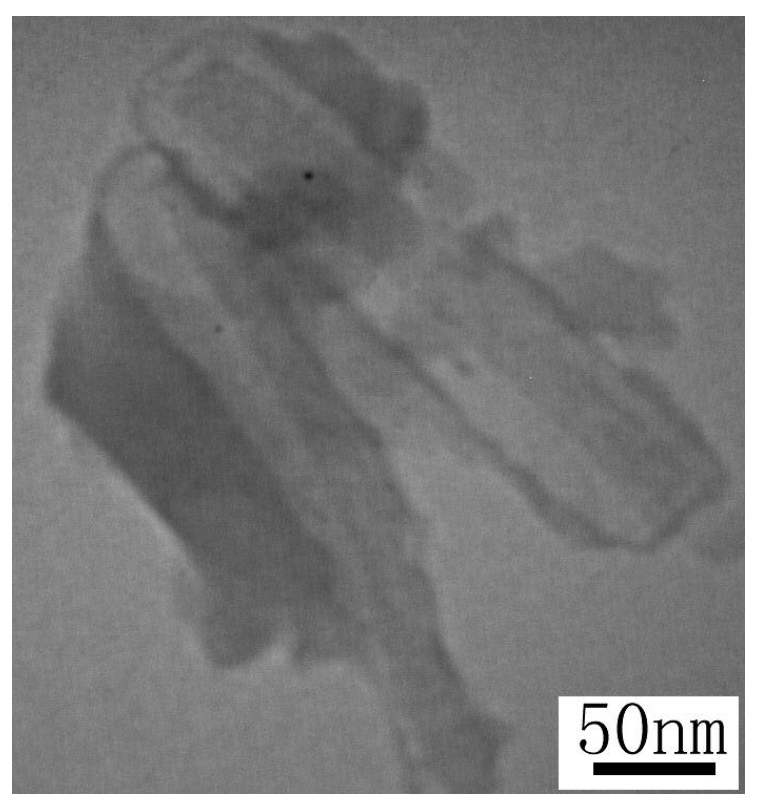

(a) 


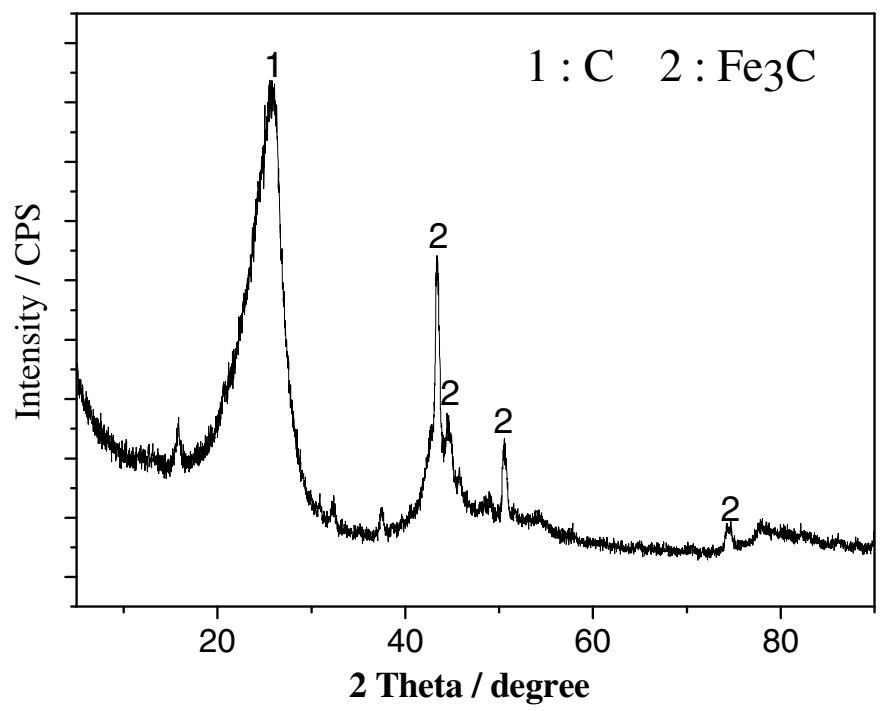

(b)

Figure S1 (a) TEM image and (b) XRD pattern of carbon nanotubes obtained after acid treatment of Sample D by hydrochloric acid $(\mathrm{HCl})$.

Notes: Sample D (carbon nanotubes obtained with further carbonization at $1000^{\circ} \mathrm{C}$ for $1 \mathrm{~h}$ )

Figure S1 shows TEM image and XRD pattern of carbon nanotubes obtained after acid treatment of Sample D by hydrochloric acid $(\mathrm{HCl})$. From Figure S1 (a), the grayish nanotubes were obtained after acid-treatment, which we believe to be carbonaceous because the nanotubes contrast is close to that of carbon while iron species is darker in contrast. Figure S1 (b) shows the main peak corresponding to carbon diffraction and a few peaks to iron carbides, indicating that most of ferric species had been consumed by $\mathrm{HCl}$ except for a few iron carbides encapsulated in carbon shells and carbon remained. So the above results illustrated that carbon nanotubes were obtained after carbonization at $1000{ }^{\circ} \mathrm{C}$.

\section{SI-2 Thermogravimetric (TG) analysis of Sample A and Sample B}






Figure S2 TG curves of Sample A (carbon-encapsulated iron carbide / iron nanorods synthesized at $450{ }^{\circ} \mathrm{C}$ in the presence of ferrocene content of $30.0 \mathrm{wt} . \%$ ) and Sample $\mathrm{B}$ (ferric nanoparticles trapped inside carbon nanotubes obtained after oxidation at $250{ }^{\circ} \mathrm{C}$ for $3 \mathrm{~h}$ in air).

Figure S2 shows TG analysis of Sample A and Sample B. Thermogravimetric (TG) analysis was conducted on Netzsch STA 449C thermal analyzer from room temperature up to $1000{ }^{\circ} \mathrm{C}$ with a heating rate of $10{ }^{\circ} \mathrm{C} / \mathrm{min}$. in air. The curves are very similar for Sample A and Sample B with almost the same amount of residue containing mainly $\mathrm{Fe}_{2} \mathrm{O}_{3}$ (XRD analysis) derived from the oxidation of the encapsulated iron species. Thus, from the stoichiometric consideration the corresponding iron content in the obtained products could be the same for both samples. So it is obvious that the iron nanoparticles didn't evaporate from carbon shells as a gas during oxidation.

SI-3 High-resolution transmission electron microscope (HREM) and Energy dispersive X-ray (EDX) spectra 

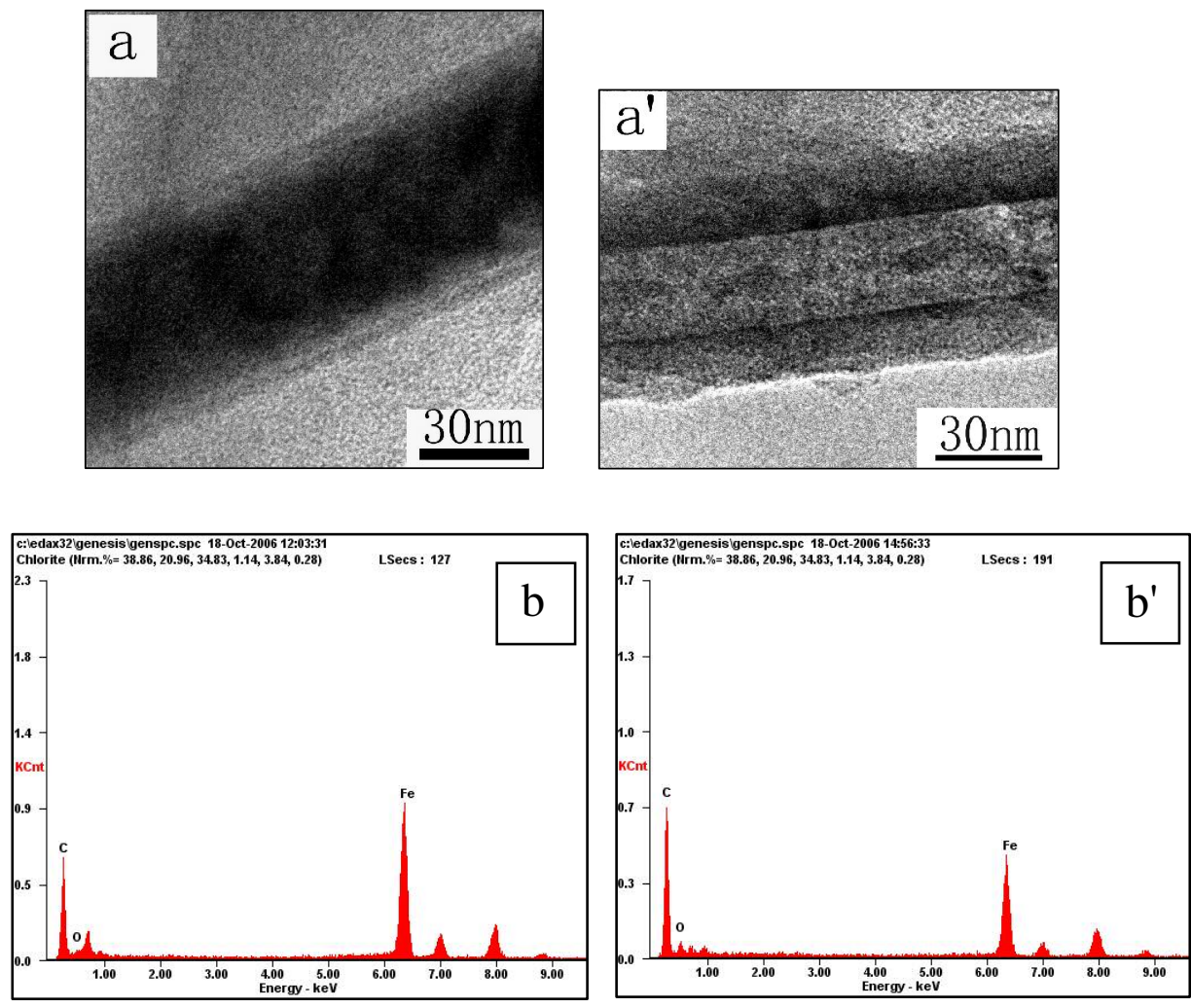

\begin{tabular}{ccc}
\hline Element & Weight\% & Atomic\% \\
\hline C K & 39.10 & 72.70 \\
O K & 02.90 & 04.10 \\
Fe K & 58.00 & 23.20
\end{tabular}

(c)

\begin{tabular}{ccc}
\hline Element & Weight\% & Atomic\% \\
\hline C K & 61.10 & 85.00 \\
O K & 04.60 & 04.80 \\
Fe K & 34.30 & 10.30
\end{tabular}

(c')

Figure S3 HREM images of (a) Sample A and (a') Sample B, EDX spectra of (b) Sample A and (b') Sample B, and Tables S3 show the corresponding composition information of (c) Sample A and (c') Sample B.

Notes: Sample A (carbon-encapsulated iron carbide / iron nanorods synthesized at 450 ${ }^{\circ} \mathrm{C}$ in the presence of ferrocene content of $30.0 \mathrm{wt} \%$ ) and Sample B (ferric nanoparticles trapped inside carbon nanotubes obtained after oxidation at $250{ }^{\circ} \mathrm{C}$ for 3 $h$ in air).

Figure S3 shows HREM images and EDX spectra of Sample A and Sample B.

HREM images and EDX spectra were carried out on JEM-3010 electron microscope.

First, we selected an individual carbon-encapsulated iron nanorod from Sample A or carbon nanotube with ferric nanoparticles trapped inside from Sample B and took the 
photo at the same magniscale as shown in (a) and (a'), respectively (at least ten of this single CENR or CNT were chosen for each sample to do the same treatment). Then under this magniscale, EDX was focused on the single nanorod (b) or nanotube (b') to obtain the composition information of samples in Sample A (c) and Sample B (c'). It can be seen that $\mathrm{Fe}, \mathrm{O}$ and $\mathrm{C}$ elements are found in both samples with elimination of $\mathrm{Cu}$ signal from the copper grid. About tens of EDX for each sample were obtained by the above way to statistically calculate the atom percent of iron to carbon (Fe/C at.\%). The average values of $\mathrm{Fe} / \mathrm{C}$ at.\% were $39.7 \%$ and $13.3 \%$ for Sample A and Sample B, respectively. Therefore, it is reasonable to deduce that about two thirds of iron species diffused and ejected from carbon shells during oxidation provided that the carbon content remained same before and after heat-treatment at $250{ }^{\circ} \mathrm{C}$ for $3 \mathrm{~h}$ in air.

\section{SI-4 TEM image}

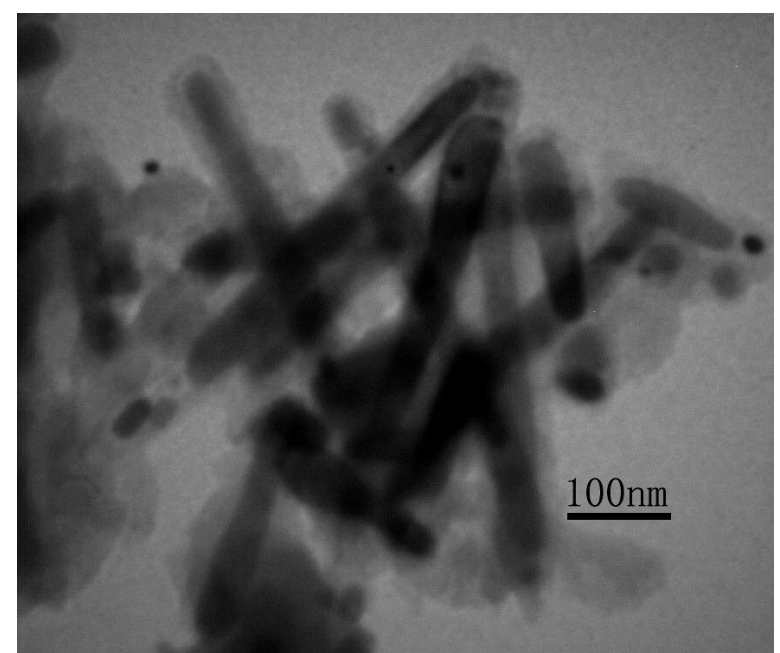

Figure S4 TEM image of carbon-encapsulated iron nanorods obtained after heat-treatment at $500{ }^{\circ} \mathrm{C}$ for $1.5 \mathrm{~h}$ and $550{ }^{\circ} \mathrm{C}$ for $1.5 \mathrm{~h}$ under $\mathrm{N}_{2}$ atmosphere. 
Figure S4 shows TEM image of carbon-encapsulated iron nanorods obtained after heat-treatment at $500{ }^{\circ} \mathrm{C}$ for $1.5 \mathrm{~h}$ and $550{ }^{\circ} \mathrm{C}$ for $1.5 \mathrm{~h}$ under $\mathrm{N}_{2}$ atmosphere. It can be seen that dark iron species were continuously enrolled in carbon shells and the length and diameter of the nanorods were centered on $150-350 \mathrm{~nm}$ and $30-50 \mathrm{~nm}$, respectively. So most of the nanorods were retained bearing the morphology of as-grown ones after heat-treatment at this temperature under inert atmosphere.

\section{SI-5 The calculation of molar reaction enthalpy}

The equation for the main oxidation reaction of iron species during oxidation at 250 ${ }^{\circ} \mathrm{C}$ in air is as follows:

$$
\mathrm{Fe}_{3} \mathrm{C}+3 \mathrm{O}_{2} \rightarrow \mathrm{Fe}_{3} \mathrm{O}_{4}+\mathrm{CO}_{2}
$$

The molar reaction enthalpy of the above equation at $250{ }^{\circ} \mathrm{C}$ can be calculated by the following Kirchhoff G R function:

$$
\Delta_{r} H_{m}^{\Phi}\left(T_{2}\right)=\Delta_{r} H_{m}^{\Phi}\left(T_{1}\right)+\int_{T_{1}}^{T_{2}} \Delta_{r} C_{p, m}^{\Phi} d T
$$

So after the input of the corresponding values, we got the final molar reaction enthalpy $-1492.61 \mathrm{~kJ} \cdot \mathrm{mol}^{-1}$. 